\title{
Repeated Ruminal Acidosis Challenges in Lactating Dairy Cows at High and Low Risk for Developing Acidosis: Feed Sorting
}

\author{
T. J. DeVries, ${ }^{* 1,2}$ F. Dohme, $†$ and K. A. Beauchemin ${ }^{*}$ \\ *Agriculture and Agri-Food Canada, Lethbridge, Alberta, Canada Agriculture and Agri-Food Canada, Research Centre, Lethbridge, \\ Alberta T1J 4B1, Canada \\ †Agroscope Liebefeld-Posieux, Research Station ALP, Posieux, Switzerland
}

\begin{abstract}
An experiment was conducted to determine whether the susceptibility of cows to ruminal acidosis influences feed sorting and whether feed sorting changes during a bout of ruminal acidosis. Eight ruminally cannulated cows were assigned to 1 of 2 acidosis risk levels: low risk (LR, mid-lactation cows fed a 60\% forage diet) or high risk (HR, early lactation cows fed a $45 \%$ forage diet). As a result, diets were intentionally confounded with milk production to represent 2 different acidosis risk scenarios. Cows were exposed to an acidosis challenge in each of two 14-d periods. Each period consisted of 3 baseline days, a feed restriction day (restricting TMR to $50 \%$ of ad libitum intake), an acidosis challenge day (1-h meal of $4 \mathrm{~kg}$ of ground barley/wheat before allocating the TMR), and a recovery phase. $\mathrm{Ru}$ minal $\mathrm{pH}$ was measured continuously for the first $9 \mathrm{~d}$ of each period using an indwelling system. Feed and orts were sampled for 2 baseline days, on the challenge day, and 1 and $3 \mathrm{~d}$ after the challenge day for each cow and subjected to particle size analysis. The separator contained 3 screens $(18,9$, and $1.18 \mathrm{~mm}$ ) and a bottom pan to determine the proportion of long, medium, short, and fine particles, respectively. Sorting was calculated as the actual intake of each particle size fraction expressed as a percentage of the predicted intake of that fraction. All cows sorted against the longest and finest TMR particles and sorted for medium-length particles. Sorting was performed to a greater extent by the HR cows, and this sorting was related to low ruminal $\mathrm{pH}$. Both HR and LR cows altered their sorting behavior in response to acidosis challenges. For the HR cows, severe acidosis was associated with increased sorting for the longer particles in the diet and against the shorter particles, likely to lessen the effects of the very
\end{abstract}

\footnotetext{
Received May 9, 2008.

Accepted June 25, 2008.

${ }^{1}$ Current address: Department of Animal and Poultry Science, University of Guelph, Kemptville Campus, 830 Prescott Street, Kemptville, Ontario, K0G 1J0, Canada.

${ }^{2}$ Corresponding author: tdevries@kemptvillec.uoguelph.ca
}

low ruminal $\mathrm{pH}$. These results suggest that feed sorting is affected by whether cows are at risk of acidosis. Furthermore, cows experiencing severe acidosis preferentially sort their feed to attenuate the effects of this condition.

Key words: acidosis, sorting, rumen $\mathrm{pH}$

\section{INTRODUCTION}

Despite the aim of providing feed as a homogenous mixture in TMR, dairy cattle will selectively consume (sort) the more palatable components of the TMR (Leonardi and Armentano, 2003; DeVries et al., 2007), causing animals to consume an imbalanced diet. Recent research indicates that lactating dairy cows demonstrate higher degrees of sorting against longer forage particles and for smaller grain concentrate particles when fed a low forage diet (DeVries et al., 2007). For early lactation cows who are typically fed low forage diets, such sorting behavior coupled with rapidly increasing DMI in weeks following calving (Kertz et al., 1991) will likely exacerbate the intake of short particles and refusal of long particles and physically effective fiber. The result is increased VFA production and reduced buffering capacity in the rumen (Cook et al., 2004; Stone, 2004). It follows that sorting may significantly contribute to the rapid increase in the severity and occurrence of ruminal acidosis that has been documented in early lactation cows (Penner et al., 2007).

Alternatively, it has been suggested that, when given the opportunity, ruminants will select a diet to help maintain a healthy ruminal environment (Cooper et al., 1996). There is growing evidence that dairy cows will select feeds with high ruminal buffering capacity in an attempt to attenuate the effects of very low ruminal $\mathrm{pH}$. Keunen et al. (2002) demonstrated that lactating dairy cows induced with subacute ruminal acidosis increased the preference for long alfalfa hay over pelleted alfalfa. Further, it has been shown that cows experiencing low ruminal $\mathrm{pH}$ will select in favor of long forage particles (Beauchemin and Yang, 2005; Yang and Beauchemin, 2006), possibly in attempt to meet their physically ef- 
fective fiber needs. Unfortunately, to date, there is no evidence to suggest that the extent to which lactating dairy cows will sort their TMR to attenuate acidosis is influenced by the severity of this condition.

The objective of this study was to determine whether lactating dairy cows that are at high or low risk for ruminal acidosis differ in their feed sorting behavior and determine how this sorting relates to measures of ruminal $\mathrm{pH}$. The hypothesis was that cows at high risk for acidosis (i.e., cows in early lactation consuming a low forage diet) would sort their TMR to a greater extent, which would relate to lower ruminal $\mathrm{pH}$. A secondary objective of this study was to determine how this sorting behavior changes in response to repeated ruminal acidosis challenges. The hypothesis was that acidosis would cause cows to alter their sorting behavior, by selecting more for the longer particles in the diet and against the shorter particles, particularly in those animals experiencing severe acidosis.

\section{MATERIALS AND METHODS}

\section{Animals, Housing, and Diets}

Eight multiparous Holstein cows were used in the study. The cows were housed in a tie-stall barn located at the Agriculture and Agri-Food Canada Lethbridge Research Centre (Alberta, Canada) and were managed according to the guidelines set by the Canadian Council on Animal Care (1993). Before starting the study, the experimental protocol was approved by the Research Centre's Animal Care Committee. The experiment was designed as a completely randomized design with 2 groups (high and low acidosis risk scenarios) and 2 repeated measures (periods) corresponding to 2 acidosis challenges. The cows, which had been previously ruminally cannulated, were assigned to 1 of the 2 groups based on their milk production and DIM at the start of the study. The high risk (HR) cows were on average $60.0 \pm 19.4$ (mean $\pm \mathrm{SD}$ ) DIM (range: 39 to $78 \mathrm{DIM}$ ), producing $40.0 \pm 3.1 \mathrm{~kg} / \mathrm{d}$ of milk. These high producing cows were assigned to a higher energy, lower forage diet. The low risk (LR) cows were on average 105.0 \pm 85.7 DIM (range: 53 to 232 DIM), producing $34.0 \pm 1.6$ $\mathrm{kg} / \mathrm{d}$ of milk. These animals were assigned to a lower energy, higher forage diet. Thus, in this study, diets were intentionally confounded with milk production to represent 2 different acidosis risk scenarios.

The forage to concentrate ratio (DM basis) of the TMR was 45:55 for the HR cows and 60:40 for the LR cows (Tables 1 and 2). Both experimental diets were formulated using the Cornell-Penn-Miner System (CPM Dairy, Version 3.0.4a; University of Pennsylvania, Kennett Square, PA, Cornell University, Ithaca, NY,
Table 1. Ingredient composition of the diets fed to cows at high and low risk for ruminal acidosis (DM basis)

\begin{tabular}{|c|c|c|}
\hline \multirow[b]{2}{*}{ Ingredient, \% of DM } & \multicolumn{2}{|c|}{ Ruminal acidosis risk } \\
\hline & High risk & Low risk \\
\hline $\begin{array}{l}\text { Barley silage }{ }^{1} \\
\text { Chopped grass-legume hay }{ }^{2} \\
\text { Corn grain, dry-rolled } \\
\text { Barley grain, steam-rolled } \\
\text { Canola oil } \\
\text { Pelleted supplement } \\
\text { Ground barley } \\
\text { Ground corn } \\
\text { Canola meal (heat treated, Alberta Gold) } \\
\text { Treated soybean meal (Soy Pass) } \\
\text { Beet pulp } \\
\text { Corn gluten meal } \\
\text { Molasses, beet } \\
\text { Limestone } \\
\text { Dicalcium phosphate } \\
\text { Sodium bicarbonate } \\
\text { Flavor (Anise } 422 \text { Powder) } \\
\text { Trace mineralized salt }\end{array}$ & $\begin{array}{r}39.6 \\
5.5 \\
8.0 \\
19.6 \\
1.4 \\
25.9 \\
3.67 \\
0.13 \\
5.38 \\
5.35 \\
3.09 \\
4.42 \\
1.67 \\
0.45 \\
0.70 \\
0.39 \\
0.01 \\
0.64\end{array}$ & $\begin{array}{r}52.7 \\
7.4 \\
2.4 \\
10.6 \\
2.6 \\
24.3 \\
3.35 \\
0.12 \\
5.06 \\
5.02 \\
2.90 \\
4.15 \\
1.57 \\
0.43 \\
0.66 \\
0.39 \\
0.01 \\
0.64\end{array}$ \\
\hline 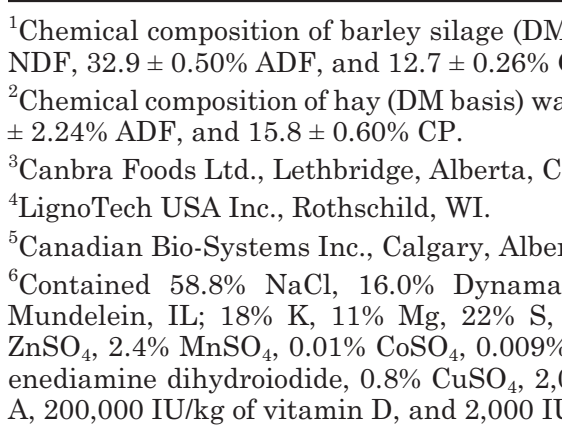 & $\begin{array}{l}\text { basis) was } \\
\mathrm{P} \text {. } \\
52.2 \pm 2.43 \\
\text { nada. } \\
\text { a, Canada. } \\
\text { (Pitman } \\
, 000 \mathrm{mg} \text { of } \\
\mathrm{Na}_{2} \mathrm{SeO}_{3}, 0 \\
00,000 \mathrm{IU} / \mathrm{k} \\
/ \mathrm{kg} \text { of vitam }\end{array}$ & $\begin{array}{l}9.0 \pm 1.28 \% \\
\mathrm{NDF}, 37.9 \\
\\
\text { Moore Inc., } \\
\text { Fe/kg), } 2 \% \\
12 \% \text { ethyl- } \\
\text { of vitamin } \\
\text { n E. }\end{array}$ \\
\hline
\end{tabular}

and William H. Miner Agricultural Research Institute, Chazy, NY). The TMR was offered ad libitum 3 times daily at 0600,1500 , and $1800 \mathrm{~h}$. The amount of feed offered to each animal was adjusted daily to ensure approximately $10 \%$ orts. The actual orts averaged $12.9 \pm$ 6.8 (mean $\pm \mathrm{SD}$ ) \% DM of offered feed over the course of the experiment. The cows had continuous access to water. They were housed in tie-stalls on rubber mats bedded with wood shavings and were milked twice daily at 0630 and $1600 \mathrm{~h}$ in their stalls.

\section{Acidosis Challenge Model}

After 2 wk of adaptation to the respective TMR, each cow was used in 2 consecutive experimental periods of $14 \mathrm{~d}$ each. The periods corresponded to acidosis challenges, which were based on the challenge used with dairy cows by Krause and Oetzel (2005). This model was chosen because it mimicked a rumen acidosis event that could occur on farm due to improper feed delivery or poor diet formulation.

Each period started with 3 baseline days (d 1, 2, 3) where the cows had ad libitum access to the TMR. 
During the following day ( $\mathrm{d} 4$, restricted feeding day) the feed was restricted to $50 \%$ of the ad libitum intake measured on $d 1$ to 3 and offered in 2 meals at 0600 and $1500 \mathrm{~h}$. In the morning of $\mathrm{d} 5$, the challenge day, acidosis was induced by feeding $4 \mathrm{~kg}$ (as-fed basis) of ground barley and wheat (1:1) at $0600 \mathrm{~h}$ for $1 \mathrm{~h}$ followed by TMR ad libitum. During the remaining days (d 6 to 14) cows once again received TMR ad libitum.

\section{Feed Sampling and Analysis}

Representative samples of the diets were collected in duplicate (one for analysis of particle size distribution, one for chemical analysis) on d 1, 3, 5, 6, and 9 of each challenge period. Similarly, duplicate samples of the orts from each animal were taken on $\mathrm{d} 2,4,6,7$, and 10 (corresponding to the feed offered on the previous days). To ensure representative samples of the orts, the entire amount of orts from each animal was split down to the required sample size using a sample splitter (Model SP-2, Gilson Co. Inc., Worthington, OH). The samples of the TMR taken for chemical analysis were composited by period. The orts samples taken for chemical analysis were composited by cow and period. Samples of chopped alfalfa-grass hay, rolled corn, barley, and concentrate were collected twice per period and composited by period. Duplicate samples of barley silage, for the analyses of particle size distribution and chemical composition, were sampled 4 times per period and composited by period. All samples were immediately frozen at $-20^{\circ} \mathrm{C}$ until they were further analyzed.

Feed samples for chemical analysis were dried at $55^{\circ} \mathrm{C}$ for $48 \mathrm{~h}$ and then ground to pass a $1-\mathrm{mm}$ screen (Wiley mill, standard model 4; Arthur H. Thomas Co., Philadelphia, PA). Analytical DM content of the samples was determined by drying at $135^{\circ} \mathrm{C}$ for $3 \mathrm{~h}$ (Method 930.05; AOAC, 1995). Acid detergent fiber and NDF were analyzed using an Ankom 200/220 Fiber Analyzer (Ankom Technology Corporation, Fairport, $\mathrm{NY}$ ) according to the methodology supplied by the company, which is based on the methods described by Van Soest et al. (1991). Heat stable a-amylase and sodium sulphite were used in the NDF procedure. The $\mathrm{N}$ content for $\mathrm{CP}$ calculation $(\mathrm{CP}=\mathrm{N} \times 6.25)$ was determined by flash combustion (Carlo Erba Instruments, Milan, Italy). Starch was determined enzymatically after gelatinization as described by Rode et al. (1999).

The individual daily samples for particle size separation were separated using the 3 -screen (19, 8, and 1.18 $\mathrm{mm}$ ) Penn State Particle Separator (PSPS; Kononoff et al., 2003). This device separated the samples into 4 particle size fractions: long (19-mm screen), medium (8-mm screen), short (1.18-mm screen), and fine (pan).
Table 2. Nutrient composition of the diets fed to lactating dairy cows at high and low risk of experiencing ruminal acidosis (mean \pm SD).

\begin{tabular}{lcc}
\hline & \multicolumn{2}{c}{ Ruminal acidosis risk } \\
\cline { 2 - 3 } Chemical composition & High risk & Low risk \\
\hline DM, \% & $59.8 \pm 0.43$ & $53.7 \pm 0.72$ \\
CP, \% of DM & $18.3 \pm 0.58$ & $18.7 \pm 0.89$ \\
NDF, \% of DM & $34.1 \pm 1.87$ & $40.1 \pm 0.39$ \\
Forage NDF, ${ }^{1} \%$ of NDF & 67 & 80 \\
ADF, \% of DM & $22.2 \pm 1.69$ & $26.3 \pm 0.56$ \\
NFC, ${ }^{1} \%$ & 40.0 & 32.0 \\
Starch, \% & $29.7 \pm 1.29$ & $21.4 \pm 0.96$ \\
Predicted $\mathrm{NE}_{\mathrm{L}},{ }^{1}$ Mcal/kg of DM & 1.60 & 1.49 \\
\hline
\end{tabular}

${ }^{1}$ Calculated values based on equations in CPM Dairy (Version 3.0.4a; University of Pennsylvania, Kennett Square, PA, Cornell University Ithaca, NY, and William H. Miner Agricultural Research Institute, Chazy, NY).

After separation, the DM of each separated fraction was determined by oven drying at $55^{\circ} \mathrm{C}$ for $48 \mathrm{~h}$. The particle fractions for the TMR samples were then ground to pass a 1-mm screen (Wiley mill, standard model 4; Arthur H. Thomas Co., Philadelphia, PA) and analyzed for NDF and starch using the above-mentioned procedures.

\section{Ruminal $\mathrm{pH}$}

Ruminal $\mathrm{pH}$ was continuously measured from $\mathrm{d} 1$ to 9 of each experimental period using the Lethbridge Research Centre Ruminal pH Measurement System (LRCpH; Dascor, Escondido, CA) as described in detail by Penner et al. (2006). Ruminal $\mathrm{pH}$ readings were taken every $30 \mathrm{~s}$. The calibration of the electrodes and the transfer of the data were carried out every $3 \mathrm{~d}$ according to Penner et al. (2007). The ruminal $\mathrm{pH}$ data were averaged each minute and summarized daily as nadir, maximum, $\mathrm{pH}$ range (difference between nadir and maximum $\mathrm{pH}$ ), and mean $\mathrm{pH}$.

\section{Calculations and Statistical Analysis}

Sorting was determined for each cow for $5 \mathrm{~d}$ during each challenge period: $\mathrm{d} 1$ (87 to $63 \mathrm{~h}$ before the acidosis challenge), d 3 (39 to $15 \mathrm{~h}$ before the acidosis challenge), d 5 (9 to $33 \mathrm{~h}$ after the acidosis challenge), d 6 (33 to $57 \mathrm{~h}$ after the acidosis challenge), and $\mathrm{d} 9$ (129 to $153 \mathrm{~h}$ after the acidosis challenge). Sorting was calculated as the actual DMI of each fraction of the PSPS expressed as a percentage of the predicted DMI of that fraction (Leonardi and Armentano, 2003). The actual intake of each individual fraction was calculated as the difference between the DM amount of each fraction in the offered TMR and that in the refused feed. The predicted intake for each individual fraction was 
calculated as the product of the DM intake of the total diet multiplied by the DM percentage of that fraction in the TMR fed. Values equal to $100 \%$ indicate no sorting, $<100 \%$ indicate selective refusals (sorting against), and $>100 \%$ indicate preferential consumption (sorting for).

To test whether sorting of the experimental diets occurred, sorting for each fraction of the PSPS was summarized by day within period for each cow, and tested for a difference from 100 using a $t$-test. To test if sorting was influenced by acidosis risk and the acidosis challenges, the data were analyzed using the MIXED procedure (SAS Institute, 2003). The model included the fixed effects of acidosis risk (LR, HR), challenge period (1, 2) and day (1, 3, 5, 6, and 9), all 2-way interactions, and the 3 -way interaction. Cow within risk category was considered a random effect, and challenge period and day within period were considered repeated measures. The covariance structure of unstructured by compound symmetry was selected on the basis of best fit according to Schwarz's Bayesian information criterion. There were day $\times$ risk $\times$ challenge period interactions for nearly all variables and, thus, the effect of day on sorting was examined by risk category within each period using MIXED procedure (SAS Institute, 2003). The model included the fixed effect of day (1, $3,5,6$, and 9). Cow was considered a random effect and day was considered as a repeated measure. The covariance structure compound symmetry was selected

Table 3. Particle size distribution of the diets and NDF and starch content of the particle fractions fed to lactating dairy cows at high and low risk of experiencing ruminal acidosis (mean $\pm \mathrm{SD}$ ).

\begin{tabular}{lrr}
\hline & \multicolumn{2}{c}{ Ruminal acidosis risk } \\
\cline { 2 - 3 } Particle size $^{1}$ & High risk & Low risk \\
\hline \% DM retained on screen & \\
$\quad$ Long & & \\
Medium & $8.7 \pm 1.3$ & $14.3 \pm 2.9$ \\
Short & $35.6 \pm 4.1$ & $37.6 \pm 3.1$ \\
Fine & $44.4 \pm 2.6$ & $39.7 \pm 2.3$ \\
NDF, ${ }^{3}$ \% of screen DM & $11.3 \pm 1.4$ & $8.5 \pm 1.3$ \\
Long & & \\
Medium & $63.8 \pm 0.6$ & $64.3 \pm 0.5$ \\
Short & $37.3 \pm 2.4$ & $44.3 \pm 2.1$ \\
Fine & $25.5 \pm 1.1$ & $29.5 \pm 0.8$ \\
Starch, ${ }^{3} \%$ of screen DM & $23.6 \pm 0.8$ & $28.8 \pm 0.8$ \\
Long & & \\
Medium & $3.1 \pm 0.6$ & $4.0 \pm 3.3$ \\
Short & $18.7 \pm 1.7$ & $15.6 \pm 3.6$ \\
Fine & $39.4 \pm 4.6$ & $36.0 \pm 3.8$ \\
\hline
\end{tabular}

${ }^{1}$ Particle size determined by Penn State Particle Separator which has a 19 -mm screen (long), 8-mm screen (medium), 1.18-mm screen (short), and a pan (fine).

${ }^{2}$ Mean for each particle size fraction based on 10 samples per acidosis risk category.

${ }^{3}$ Mean for each particle size fraction based on 4 samples per acidosis risk category on the basis of best fit according to Schwarz's Bayesian information criterion. The effects of days for each risk category within challenge period were examined using contrast statements. Baseline sorting measurements (d 1 and 3) were compared with sorting that occurred during the day following the challenge ( $\mathrm{d} 5$; $\mathrm{d}-1$ postchallenge), during the second day following the challenge (d 6; d-2 postchallenge), and during the recovery day (d 9). Significance was declared at $P \leq 0.05$, and a trend was reported if $0.05<P \leq 0.15$.

The regression procedure of SAS (SAS Institute, 2003) was used to determine the relationship between sorting and ruminal $\mathrm{pH}$. To address our first hypothesis, a stepwise regression was used to identify whether sorting of the particle size fractions made significant contributions to predicting measures of ruminal $\mathrm{pH}$ during the baseline period (d 1 and 3). To address our second hypothesis, a stepwise regression was used to identify if the various ruminal $\mathrm{pH}$ variables made significant contributions to predicting the sorting of the particle size fractions during the day following the challenge ( $\mathrm{d}-1$ postchallenge). For both models, the level of significance for a variable to enter and to stay in the model, respectively, was $P \leq 0.15$.

\section{RESULTS}

\section{Dietary Composition}

Nutrient composition and particle size distribution of the diets are reported in Tables 2 and 3, respectively. The diet fed to the LR cows had a lower DM and starch content, but greater NDF, ADF, and NDF from forages content than the diet fed to the HR cows. With a decreased amount of forage in the ration fed to the HR cows, there was a decreased proportion of long particles and an increased proportion of short and fine particles. The NDF content of the medium, short, and fine particle fractions was greater for the ration fed to the LR cows. The starch content of the long particle fraction was greater in the ration fed to the LR cows, but was lesser for the medium, short, and fine particle fractions as compared within the ration fed to the HR cows.

\section{Sorting}

All cows sorted, to the same extent, against long particles regardless of acidosis risk or challenge periods (Table 4). All cows also sorted for medium particles, but the extent of the sorting for medium particles increased from period 1 to 2 for all cows and was greater across periods for the HR cows. There was also a difference between risk categories in sorting of short particles; 
on average, across the experiment, the HR cows sorted against whereas the LR cows sorted for short particles. From period 1 to 2 there was a tendency for the HR cows to increase their sorting against short particles and for the LR cows to decrease their sorting for short particles. With the exception of the LR cows in period 1 , cows sorted against fine particles regardless of acidosis risk or challenge period. This sorting against fine particles was greatest in the HR cows, and increased from period 1 to 2 for cows in both risk categories.

There was a day effect for sorting of medium $(P<$ $0.01)$ and fine $(P<0.1)$ particles. There was a day $\times$ risk effect $(P<0.1)$ for sorting of long particles and a challenge period $\times$ day effect $(P<0.01)$ for sorting of all the particle sizes. Further, there was a day $\times$ risk $\times$ challenge period effect $(P<0.05)$ for sorting of long, short, and fine particles. Due to all of these interactions, the effect of day on sorting was examined by risk category within each period (Figure 1). Baseline sorting measurements (d 1 and 3 ) were compared with the day following challenge ( $\mathrm{d} 5 ; \mathrm{d}-1$ postchallenge), the second day following the challenge (d 6; d-2 postchallenge), and to the recovery day (d 9). The HR cows in period 1 increased their sorting for medium particles, and against short and fine particles on $\mathrm{d}-2$ postchallenge, but returned to baseline activity by the recovery day (Figure 1a). In period 2, the HR cows tended to increase their sorting for medium particles, tended to increase their sorting against short particles, and dramatically increased their sorting against fine particles on $\mathrm{d}-1$ postchallenge (Figure $1 \mathrm{~b}$ ). There was a tendency for decreased sorting for medium particles and against short particles during d-2 postchallenge. By the recovery day, the level of sorting of these cows had returned to the baseline values. The LR cows in period 1 , as compared with the baseline days, decreased their sort- ing against long particles on $\mathrm{d}-1$ postchallenge, then increased their sorting against long particles on d-2 postchallenge, and then had a tendency to decrease their sorting against long particles on the recovery day (Figure 1c). These cows also increased their sorting for medium particles and against fine particles on d-2 postchallenge, but returned to baseline sorting of these fractions by the recovery day. In period 2, the LR cows increased their sorting against long particles on $\mathrm{d}-1$ postchallenge, then returned to baseline on $\mathrm{d}-2$ postchallenge, but by the recovery day they had again increased their sorting against long particles (Figure 1d). These cows tended to increase their sorting for medium particles on d-1 postchallenge, and then tended to decrease their sorting for medium particles on d-2 postchallenge, and return to baseline sorting for medium particles on the recovery day. The LR risk in period 2 changed from sorting against during the baseline days and $\mathrm{d}-1$ postchallenge to sorting for small and fine particles on $\mathrm{d}-2$ postchallenge; this continued on the recovery day.

\section{Relationship Between Ruminal pH and Sorting}

Detailed descriptions of the effects of acidosis risk and challenge period on various measures associated with ruminal $\mathrm{pH}$ are presented in Dohme et al. (2008). The final linear regression models describing the relationship between feed sorting and measures of ruminal $\mathrm{pH}$ during the baseline period of each challenge period for each risk category is presented in Table 5. For the HR cows in period 1 maximum ruminal $\mathrm{pH}$ was positively correlated to sorting of long particles. In period 2 for the HR cows, nadir $\mathrm{pH}$ was negatively correlated with sorting of medium particles. Similarly mean and maximum $\mathrm{pH}$ were negatively correlated to sorting

Table 4. Effects of repeated ruminal acidosis challenges (1 and 2) on feed sorting by lactating dairy cows at high and low risk for experiencing acidosis ${ }^{1}$

\begin{tabular}{|c|c|c|c|c|c|c|c|c|}
\hline Particle size $^{2}$ & \multicolumn{2}{|c|}{ High acidosis risk } & \multicolumn{2}{|c|}{ Low acidosis risk } & $\mathrm{SEM}^{3}$ & \multicolumn{3}{|c|}{$P$-value ${ }^{4}$} \\
\hline Medium particles & 105.3 & 107.8 & 102.1 & 103.3 & 0.55 & $<0.001$ & 0.002 & 0.2 \\
\hline Short particles & 99.0 & 97.7 & 101.6 & 101.4 & 0.56 & $<0.001$ & 0.06 & 0.14 \\
\hline Fine particles & 93.6 & 86.5 & $99.2^{5}$ & 96.1 & 2.30 & 0.004 & 0.005 & 0.2 \\
\hline
\end{tabular}

${ }^{1}$ Sorting $\%=100 \times(\mathrm{DM}$ intake of particle size $\mathrm{n} /$ predicted DM intake of particle size $\mathrm{n})$. Data are averaged for 4 cows in each risk category.

${ }^{2}$ Particle size determined by Penn State Particle Separator, which has a 19-mm screen (long), 8-mm screen (medium), 1.18-mm screen (short), and a pan (fine).

${ }^{3}$ Greatest SEM is shown.

${ }^{4}$ Day effect for medium $(P<0.01)$ and fine $(P<0.1)$ particles. Day $\times$ risk effect $(P<0.1)$ for long particles and challenge period $\times$ day effect $(P<0.01)$ for all particle sizes. Day $\times$ risk $\times$ challenge period interactions for long, short, and fine particles $(P<0.05)$. $\mathrm{R}=$ acidosis risk; $\mathrm{P}=$ challenge period.

${ }^{5}$ Not significantly $(P>0.05)$ different from $100 \%$. All other sorting values are significantly $(P<0.05)$ different from $100 \%$. 


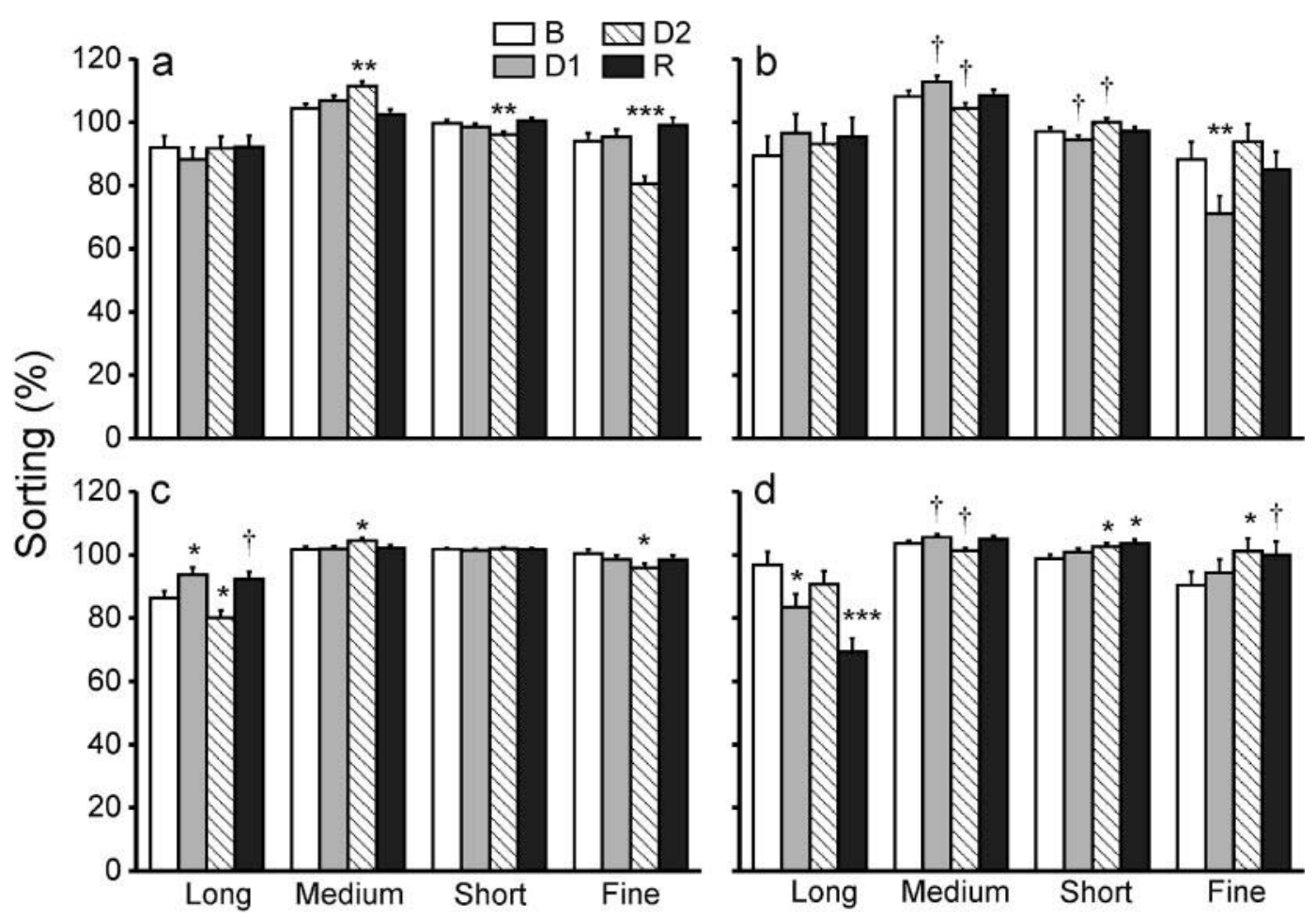

Figure 1. Sorting for long (19-mm screen), medium (8-mm screen), short (1.18-mm screen), and fine (pan) particles on the baseline days (B), d-1 postchallenge (D1), d-2 postchallenge (D2), and recovery day (R) for a) high acidosis risk cows in period 1, b) high acidosis risk cows in period 2, c) low acidosis risk cows in period 1, and d) low acidosis risk cows in period 2. Sorting $=[100 \times(\mathrm{DM}$ intake of particle size $\mathrm{n} /$ predicted DM intake of particle size n)], where values equal to $100 \%$ indicate no sorting, $<100 \%$ indicate selective refusals (sorting against), and $>100 \%$ indicate preferential consumption (sorting for). Difference in sorting from baseline days expressed as $\dagger P<0.15,{ }^{*} P<0.05,{ }^{* *} P<$ $0.01,{ }^{* * *} P<0.001$.

of medium and short particles. Also, the range in $\mathrm{pH}$ (maximum - nadir) was positively correlated to sorting of medium particles. For the LR cows in period 1 nadir $\mathrm{pH}$ was positively correlated to sorting of medium particles and negatively correlated to sorting of small particles. For these cows, maximum $\mathrm{pH}$ was negatively correlated to sorting of fine particles. Further, range in $\mathrm{pH}$ was positively correlated to sorting of long and short particles, and negatively correlated to sorting of fine particles. For the LR in period 2, nadir, mean, and maximum $\mathrm{pH}$ were all negatively correlated to sorting of short particles.

There were also several relationships determined between ruminal $\mathrm{pH}$ and sorting that occurred on $\mathrm{d}-1$ postchallenge. For the HR cows in period 2, which experienced the greatest acidosis on that day (Dohme et al., 2008), there was strong correlation between sorting of all particle fractions and maximum ruminal $\mathrm{pH}$ (Figure 2). In particular, sorting of long (Figure 2a) and medium (Figure $2 \mathrm{~b}$ ) particles were negatively correlated with maximum $\mathrm{pH}$. On the other hand, sorting of short (Figure 2c) and fine (Figure 2d) particles was positively correlated with maximum $\mathrm{pH}$. The sorting of the LR cows was also influenced by the acidosis challenge, in both periods 1 and 2 . For period 1 there were correlations with maximum $\mathrm{pH}$ for sorting of: long particles, \% $=[-57.6 \times$ maximum $\mathrm{pH}]+495.0\left(\mathrm{R}^{2}=0.91, P=0.04\right)$; medium particles, $\%=[26.8 \times$ maximum $\mathrm{pH}]-84.5\left(\mathrm{R}^{2}\right.$ $=0.91, P=0.047) ;$ short particles, $\%=[7.5 \times$ maximum $\mathrm{pH}]+49.4\left(\mathrm{R}^{2}=0.77, P=0.13\right)$; and fine particles, $\%$ $=[-29.8 \times$ maximum $\mathrm{pH}]+306.1\left(\mathrm{R}^{2}=0.88, P=0.06\right)$. For period 2 there were correlations for the LR cows with $\mathrm{pH}$ range for sorting of: short particles, $\%=[-5.2$ $\times \mathrm{pH}$ range $]+110.0\left(\mathrm{R}^{2}=0.89, P=0.05\right)$; and with mean $\mathrm{pH}$ and range for sorting of fine particles, $\%=$ $[9.1 \times$ mean $\mathrm{pH}]+[-34.9 \times \mathrm{pH}$ range $]+102.7\left(\mathrm{R}^{2}=\right.$ $0.99, P=0.07)$.

\section{DISCUSSION}

The susceptibility of dairy cows to acidosis appears to be highest for cows in early lactation (Fairfield et al., 2007; Penner et al., 2007). Much of this susceptibility can be attributed to the switch from a higher forage dry cow diet to a lower forage lactating diet, combined with rapidly increasing DMI in early lactation. It has been hypothesized that the risk of acidosis also increases when dairy cows sort their TMR, typically 
Table 5. Final linear regression models ${ }^{1}$ describing the relationship between feed sorting ${ }^{2}$ and measures of ruminal $\mathrm{pH}$ during the baseline period of each challenge period for each risk category ${ }^{3}$

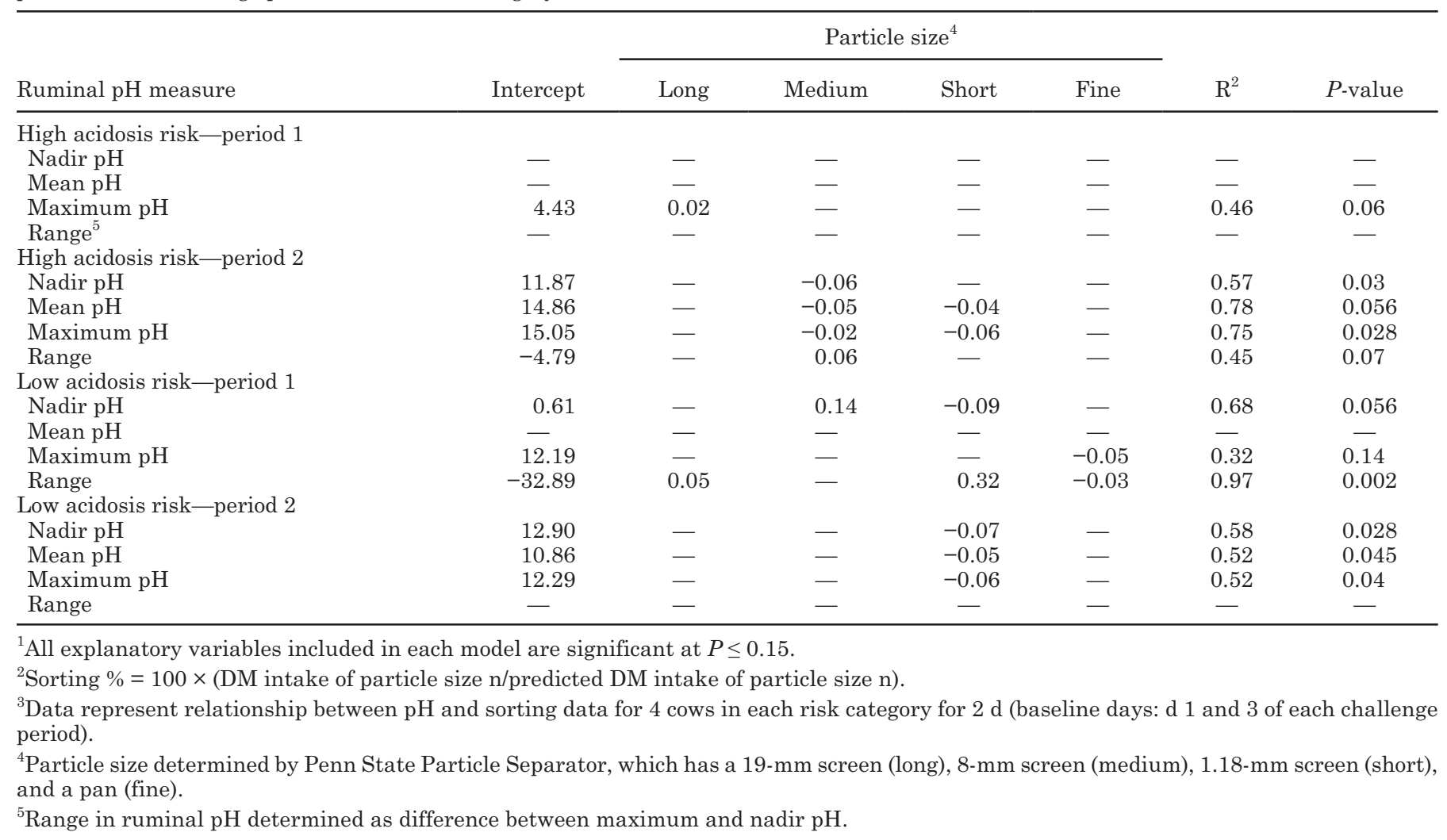

in favor of short particles and against long particles and physically effective fiber. We were, therefore, interested in determining whether cows would differ in their feed sorting behavior based on their acidosis risk. To achieve this, we tested 2 risk scenarios for acidosis: HR consisting of dairy cows in early lactation fed a low forage diet and LR consisting of cows in mid-lactation fed a higher forage diet. The rations used in this study were, therefore, not designed to have similar composition, but rather vary in particle size distribution and nutrient density to match the requirements of the animals. The diet fed to the LR cows had a lower DM and starch content, but greater NDF, ADF, and NDF from forages content than the diet fed to the HR cows. With a decreased amount of forage in the diet fed to the HR cows, there was decreased proportion of long particles and increased proportion of short and fine particles. The NDF and starch content of the various particle size fractions differed based on the rations fed and would therefore affect the sorting behavior of the HR and LR cows in different ways.

Regardless of the type of diet consumed, the cows sorted, to a similar extent, against long particles. This result is not surprising as most research on feed sorting has reported that cattle sort extensively against long particles, regardless of the substrate making up the bulk of the long particle fraction (Leonardi and Armentano, 2003; DeVries et al., 2007). All of the cows also sorted for medium particles and against fine particles. This is a remarkably different finding than that reported in other recent studies on feed sorting, where negligible sorting of medium particles and sorting for the smallest particles in the rations was found (DeVries et al., 2007; Hosseinkhani et al., 2008). This difference can be explained if one considers the composition of the particle fractions in the present study. It is likely that the cows were primarily sorting for the supplement pellet that made up part of the medium particle fraction. Given the low NDF and moderate starch content of the fine particle fraction, the sorting against these particles is surprising. In other studies it has been reported that cows sort for fine particles (Leonardi and Armentano, 2003; Hosseinkhani et al., 2008). Sorting against the fine particles likely corresponds to the cows not consuming the particles that had fallen to the manger floor as the cows moved the TMR around and sorted through it. On average the HR cows sorted against short particles, whereas the LR cows sorted for these particles. This finding, however, may not be biologically meaningful because there was 


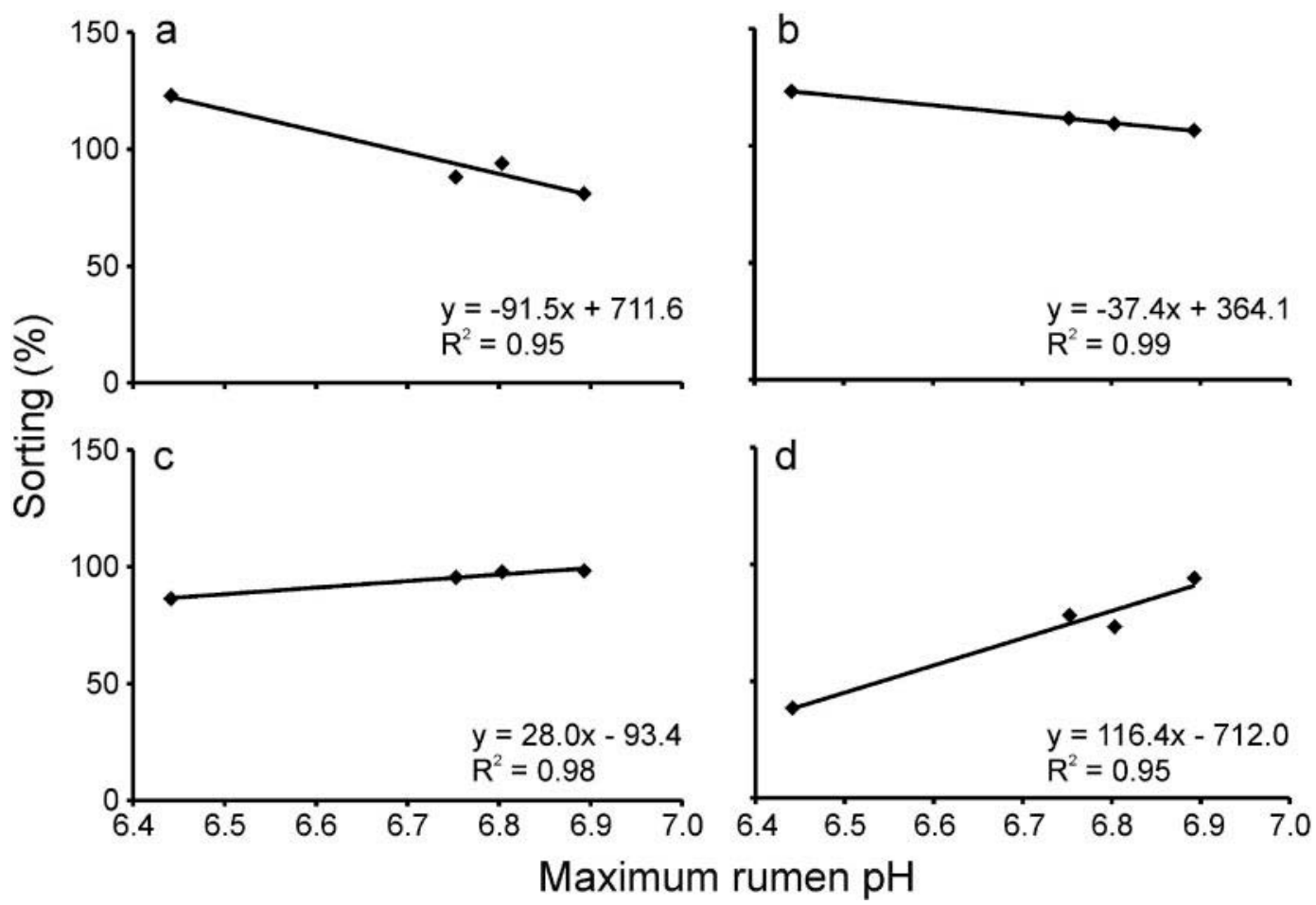

Figure 2. Linear regression models $(P<0.05)$ describing the relationship between maximum ruminal $\mathrm{pH}$ and sorting for a) long $(19$-mm screen), b) medium (8-mm screen), c) short (1.18-mm screen), and d) fine (pan) particles for high acidosis risk cows on the challenge day during the second challenge period. Sorting $=[100 \times(\mathrm{DM}$ intake of particle size $\mathrm{n} /$ predicted DM intake of particle size $\mathrm{n})]$, where values equal to $100 \%$ indicate no sorting, $<100 \%$ indicate selective refusals (sorting against), and $>100 \%$ indicate preferential consumption (sorting for),

minimal sorting (i.e., consumption similar to that predicted) of short particles detected for either group of cows across both periods ( $<3 \%$ sorting against by the HR cows, $<2 \%$ for by the LR cows).

The sorting behavior of the cows may have been influenced, in part, by some of the feeding management practices used in this study. The level of overfeeding, as reflected in the percentage of orts, was higher than that which is typically done on commercial dairies. This overfeeding was done to ensure that cows did not consume all their feed and that sorting occurred. It is possible that the degree of sorting may have been slightly exacerbated by the level of overfeeding because there is evidence to suggest that the amount of feed offered can influence the degree of feed sorting (Leonardi and Armentano, 2007). Alternatively, the high frequency of feed delivery $(3 \times)$ in the current study may have suppressed the degree of sorting as compared with many commercial settings where feeding once per day is common. Previous research on feeding frequency has indicated that delivery of feed at least 2 times per day or more reduces the degree feed sorting as compared with feeding once per day (DeVries et al., 2005).

Overall, the extent of the sorting for medium particles and against fine particles was greatest for the
HR cows. This finding is similar to that of DeVries et al. (2007), who also found that cows performed more sorting when fed a lower forage diet compared with a higher forage diet. The differences in sorting between the 2 groups in the present study could be explained by various factors, including differences in diet palatability, the greater dietary DM content of the TMR fed to HR cows (Leonardi et al., 2005), and the greater proportion of short and fine particles in the TMR fed to HR cows.

Regardless of the cause of sorting, this behavior can be problematic, especially for HR cows. DeVries et al. (2007) found that for cows consuming a lower forage diet, the actual intake of physically effective fiber was much less than predicted due to sorting. For early lactation cows, greater sorting of a higher concentrate, lower fiber diet, coupled with rapidly increasing DMI (Kertz et al., 1991), will exacerbate the intake of highly fermentable carbohydrates and refusal of physically effective fiber. To date, it has been hypothesized that such sorting will result in increased VFA production, decreased buffering capacity, and increased risk of subacute ruminal acidosis (Cook et al., 2004; Stone, 2004; Krause and Oetzel, 2006). To our knowledge, the results of the present study are the first to support this 
theory, as demonstrated by the strong relationships observed between feed sorting and measures of ruminal $\mathrm{pH}$ during the baseline days of each challenge period.

In support of our first hypothesis, not only did the HR cows sort their TMR to a greater extent, but also this sorting was related to lower ruminal $\mathrm{pH}$. For the HR cows in period 1, it was found that the more the sorting against long particles that cows performed, the lower their maximum ruminal $\mathrm{pH}$. This is not surprising given that the long particle fraction was mostly high fiber, long forage particles. Decreased consumption of such physically effective fiber would reduce rumination and ruminal buffering capacity and thus prevent ruminal $\mathrm{pH}$ from being restored to more neutral levels. For the HR cows in period 2, it was found that the more the sorting for medium and short particles, the lower the nadir, mean, and maximum ruminal $\mathrm{pH}$. It is likely that the increased intake of these moderate and high starch content fractions depressed ruminal $\mathrm{pH}$. The greater range in ruminal $\mathrm{pH}$ associated with the sorting of medium particles could also be explained by such depression of ruminal $\mathrm{pH}$. For the LR cows in period 1 , increased sorting of medium particles was associated with higher nadir $\mathrm{pH}$, whereas increased sorting of short particles was associated with lower nadir $\mathrm{pH}$. For these cows, maximum $\mathrm{pH}$ decreased with increased sorting of fine particles. Similar to the HR cows in period 2, it was found for the LR cows in that period that the more the sorting for short particles, the lower the nadir, mean, and maximum ruminal $\mathrm{pH}$. Together, these results show that increased sorting of particle fractions that were higher in starch and lower in NDF reduced ruminal $\mathrm{pH}$ variables, although the specific $\mathrm{pH}$ variable that correlated best with the sorting variable differed between diets and between periods.

Cows changed their sorting behavior upon the acidosis challenge. For the HR cows in period 1, there were some small adjustments to sorting behavior, particularly on d-2 postchallenge. In period 2 , the HR cows that experienced the greatest acidosis (Dohme et al., 2008), dramatically changed their sorting behavior, particularly on d-1 postchallenge. These cows increased the sorting for medium particles and decreased sorting of short and fine particles. These results suggest that the cows were attempting to increase their physically effective fiber intake (i.e., forage particles within the medium fraction), and reduce their starch intake (i.e., grain particles within the short and fine fractions), possibly to attenuate the effects of the very low ruminal $\mathrm{pH}$ that animals were experiencing during that period. The regression data corroborate this hypothesis in that the cows with the lowest ruminal $\mathrm{pH}$ performed the most sorting for longer particles in the diet, while sorting against the shorter particles. The LR cows in both period 1 and 2 also changed their sorting behavior in response to the acidosis challenge. Most of these changes occurred on d-2 postchallenge and the recovery day when $\mathrm{pH}$ had returned to baseline values. There were some associations detected between sorting and ruminal $\mathrm{pH}$ on $\mathrm{d}-1$ postchallenge for both periods for the LR cows. Those cows with the lowest maximum ruminal $\mathrm{pH}$ during $\mathrm{d}-1$ postchallenge in period 1 sorted more for long and fine particles, and less for medium and short particles. In period 2, a greater range in ruminal $\mathrm{pH}$ for the LR cows resulted in less sorting for short and fine particles, whereas lower mean ruminal $\mathrm{pH}$ also resulted in less sorting for fine particles.

Overall, there were clear associations between sorting and ruminal $\mathrm{pH}$ on $\mathrm{d}-1$ postchallenge for both LR and HR cows. The change in sorting behavior on that day for the HR cows corroborates our hypothesis that acidosis would cause cows to alter their sorting behavior, particularly in those animals experiencing severe acidosis. Furthermore, the alteration of TMR sorting in response to the acidosis challenge provides further support for the theory that ruminants will alter their feeding behavior to rectify maladies that they incur (Provenza, 1995). Researchers have previously shown that ruminants will alter their diet selection in response to low ruminal $\mathrm{pH}$, including the selection of sodium bicarbonate (Cooper et al., 1996; Phy and Provenza, 1998), preferring long hay over pelleted forage (Keunen et al., 2002), and sorting a TMR for long particles when fed diets that caused low ruminal $\mathrm{pH}$ (Beauchemin and Yang, 2005; Yang and Beauchemin, 2006). The results of the present study are the first evidence to suggest that the severity of acidosis will influence the extent by which lactating dairy cows will sort their TMR to attenuate this condition. It is interesting to point out that before the acidosis challenge, the sorting behavior of these cows likely contributed to lowering their rumen $\mathrm{pH}$. Further research is needed to determine the exact point at which the acidosis becomes severe enough for the cows to alter their sorting behavior in attempt to increase rumen $\mathrm{pH}$. Also, given the relatively short duration of the ruminal acidosis following the challenge (Dohme et al., 2008), it was not possible to determine what role the altered sorting had in attenuating the acidosis. A future study is needed to determine if cows can attenuate acidosis through altered sorting behavior during a prolonged acidosis event.

\section{CONCLUSIONS}

Early lactation cows fed a low forage diet and midlactation cows fed a high forage diet both sorted against the longest and finest TMR particles and sorted for medium length TMR particles. Sorting was performed to a 
greater extent by the cows at high risk for acidosis, and this sorting was related to low ruminal $\mathrm{pH}$. The HR and LR cows altered their sorting behavior in response to acidosis challenges. For the HR cows, severe acidosis was associated with increased sorting for the longer particles in the diet and against the shorter particles, likely to attenuate the effects of the very low ruminal $\mathrm{pH}$. These results suggest that feed sorting is affected by acidosis risk of cows. Furthermore, cows experiencing severe acidosis preferentially sort their feed to attenuate the effects of this condition.

\section{ACKNOWLEDGMENTS}

We thank Bev Farr (Agriculture and Agri-Food Canada Lethbridge Research Centre) for her invaluable technical assistance in conducting the experiment, $\mathrm{T}$. Entz (Agriculture and Agri-Food Canada Lethbridge Research Centre) for his advice with the statistical analysis, M. Krause (West Virginia University) for her helpful advice on conducting the ruminal acidosis challenges, and the Lethbridge Research Centre farm staff for caring for the cows. F. Dohme received a fellowship from OECD. The project was funded through contributions from the Westgen Endowment Fund, Investment Agriculture Foundation of British Columbia, and Agriculture and Agri-Food Canada.

\section{REFERENCES}

AOAC. 1995. Official Methods of Analysis. 16th ed. Association of Official Analytical Chemists International, Arlington, VA.

Beauchemin, K. A., and W. Z. Yang. 2005. Effects of physically effective fiber on intake, chewing activity, and ruminal acidosis for dairy cows fed diets based on corn silage. J. Dairy Sci. 88:2117-2129.

Canadian Council on Animal Care. 1993. Guide to the care and use of experimental animals. Vol. 1. E. D. Olfert, B. M. Cross, and A. A. McWilliam, ed. CCAC, Ottawa, Canada.

Cook, N. B., K. V. Nordlund, and G. R. Oetzel. 2004. Environmental influences on claw horn lesions associated with laminitis and subacute ruminal acidosis in dairy cows. J. Dairy Sci. 87:E36E46.

Cooper, S. D., I. Kyriazakis, and J. D. Oldham. 1996. The effects of physical form of feed, carbohydrate source, and inclusion of sodium bicarbonate on the diet selections of sheep . J. Anim. Sci. 74:1240-1251.

DeVries, T. J., K. A. Beauchemin, and M. A. G. von Keyserlingk. 2007. Dietary forage concentration affects the feed sorting behavior of lactating dairy cows. J. Dairy Sci. 90:5572-5579.

DeVries, T. J., M. A. G. von Keyserlingk, and K. A. Beauchemin. 2005. Frequency of feed delivery affects the behavior of lactating dairy cows. J. Dairy Sci. 88:3553-3562.

Dohme, F., T. J. DeVries, and K. A. Beauchemin. 2008. Repeated ruminal acidosis challenges in lactating dairy cows at high and low risk for developing acidosis: Ruminal pH. J. Dairy Sci. 91:3554-3567.

Fairfield, A. M., J. C. Plaizier, T. F. Duffield, M. I. Lindinger, R. Bagg, P. Dick, and B. W. McBride. 2007. Effects of prepartum administration of a monensin controlled release capsule on rumen $\mathrm{pH}$, feed intake, and milk production of transition dairy cows. J. Dairy Sci. 90:937-945.

Hosseinkhani, A., T. J. DeVries, K. L. Proudfoot, R. Valizadeh, D. M. Veira, and M. A. G. von Keyserlingk. 2008. The effects of feed bunk competition on the feed sorting behavior of close-up dry cows. J. Dairy Sci. 91:1115-1121.

Kertz, A. F., L. F. Reutzel, and G. M. Thomson. 1991. Dry matter intake from parturition to midlactation. J. Dairy Sci. 74:22902295.

Keunen, J. E., J. C. Plaizier, L. Kyriazakis, T. F. Duffield, T. M. Widowski, M. I. Lindinger, and B. W. McBride. 2002. Effects of a subacute ruminal acidosis model on the diet selection of dairy cows. J. Dairy Sci. 85:3304-3313.

Kononoff, P. J., A. J. Heinrichs, and D. R. Buckmaster. 2003. Modification of Penn State forage and total mixed ration particle separator and the effects of moisture content on its measurements. J. Dairy Sci. 86:1858-1863.

Krause, K. M., and G. Oetzel. 2006. Understanding and preventing subacute ruminal acidosis in dairy herds: A review. Anim. Feed Sci. Technol. 126:215-236.

Krause, K. M., and G. R. Oetzel. 2005. Inducing subacute ruminal acidosis in lactating dairy cows. J. Dairy Sci. 88:3633-3639.

Leonardi, C., and L. E. Armentano. 2003. Effect of quantity, quality, and length of alfalfa hay on selective consumption by dairy cows. J. Dairy Sci. 86:557-564.

Leonardi, C., and L. E. Armentano. 2007. Feed selection by dairy cows fed individually in a tie-stall or as a group in a free-stall barn. J. Dairy Sci. 90:2386-2389.

Leonardi, C., F. Giannico, and L. E. Armentano. 2005. Effect of water addition on selective consumption (sorting) of dry diets by dairy cattle. J. Dairy Sci. 88:1043-1049.

Penner, G. B., K. A. Beauchemin, and T. Mutsvangwa. 2006. An evaluation of the accuracy and precision of a stand-alone submersible continuous ruminal $\mathrm{pH}$ measurement system. J. Dairy Sci. 89:2132-2140.

Penner, G. B., K. A. Beauchemin, and T. Mutsvangwa. 2007. Severity of ruminal acidosis in primiparous Holstein cows during the periparturient period. J. Dairy Sci. 90:365-375.

Phy, T. S., and F. D. Provenza. 1998. Sheep fed grain prefer foods and solutions that attenuate acidosis. J. Anim. Sci. 76:954-960.

Provenza, F. D. 1995. Postingestive feedback as an elementary determinant of food preference and intake in ruminants. J. Range Manage. 48:2-17.

Rode, L. M., W. Z. Yang, and K. A. Beauchemin. 1999. Fibrolytic enzyme supplements for dairy cows in early lactation. J. Dairy Sci. 82:2121-2126.

SAS Institute. 2003. SAS Users Guide. SAS Institute Inc., Cary, NC.

Stone, W. C. 2004. Nutritional approaches to minimize subacute ruminal acidosis and laminitis in dairy cattle. J. Dairy Sci. 87:E13-E26.

Van Soest, P. J., J. B. Robertson, and B. A. Lewis. 1991. Methods for dietary fiber, neutral detergent fiber and non-starch polysaccharide in relation to animal nutrition. J. Dairy Sci. 74:3583-3597.

Yang, W. Z., and K. A. Beauchemin. 2006. Effects of physically effective fiber on chewing activity and ruminal $\mathrm{pH}$ of dairy cows fed diets based on barley silage. J. Dairy Sci. 89:217-228. 